\title{
CLINICO- EPIDEMIOLOGICAL PROFILE OF ROAD TRAFFIC INCIDENTS ADMITTED AT A TERTIARY CARE HOSPITAL IN GARHWAL- UTTARAKHAND
}

Sumeet Dixit, Praveen K. Tyagi, Amit K. Singh, Sudhir K. Gupta, Nidhi Malik

1. Dr. Sumeet Dixit, Assistant professor, Department of Community Medicine, VCSGGMSRI- Srinagar, Pauri- Garhwal (Uttarakhand)

2. Dr. Praveen K. Tyagi, Assistant professor, Department of General Surgery, VCSGGMSRI- Srinagar, Pauri- Garhwal (Uttarakhand)

3. Dr. Amit K. Singh, Associate professor, Department of Community Medicine, VCSGGMSRI- Srinagar, Pauri- Garhwal (Uttarakhand)

4. Dr. Sudhir K. Gupta, Associate professor, Department of Community Medicine, VCSGGMSRI- Srinagar, Pauri- Garhwal (Uttarakhand)

5. Miss Nidhi Malik, Demonstrator, Department of Community Medicine, VCSGGMSRI- Srinagar, Pauri- Garhwal (Uttarakhand)

\section{CORRESPONDING AUTHOR:}

Dr. Amit K. Singh,

Associate Professor,

(Community Medicine),

VCSG Govt. Medical College,

Srinagar - Garhwal, Uttarakhand,

India- 246174.

Email ID- singh120377@yahoo.co.in

\section{ABSTRACT:}

BACKGROUND: The magnitude of Road traffic incidents and fatalities in India is alarming. In 2009, 4.22 lakh road traffic incidents and 1.27 lakh road traffic fatalities were reported. These numbers translate into one road accident every minute and one road accident death every four minutes METHODS: The study (based on Jorgensen and Abane model, 1999) was conducted over a period of one year during April 2011 to March 2012, among 136 victims (including 33 drivers) of road traffic incidents coming to Veer Chandra Singh Garhwali government medical college, Srinagar, Garhwal. RESULTS: 136 victims including 33 drivers were interviewed who were brought to the causality in the aforesaid period. 23 people were brought dead. There is clustering of cases from the month of August to October when compared to other months of year. $40 \%$ of drivers were drunk/or using some other substance at the time of accident. Only $12.1 \%$ of drivers were using seat belts at the time of accident. 57.6\% were having driving license and 54.5\% were either refractive error or hearing impairment or both. Human error, High speed, Lack of sleep, effect of Alcohol and mechanical fault of vehicle were reasons of accident as told by the drivers CONCLUSIONS: During August to October there is clustering of cases. This period coincides with "Char Dham Yatra" and rainy season both. Special efforts should be done during this period. Strong vigilance of drivers for

Journal of Evolution of Medical and Dental Sciences / Volume 1 / Issue 3 / July- Sept 2012 
alcohol use, presence of driving license, compulsory use of seat belts, and premedical checkup for refractive errors may prove valuable and morbidity and mortality can be minimized.

KEY WORDS: Road Traffic Incident, Determinants, Hilly region

\section{INTRODUCTION:}

Road traffic incidents which are generally unintended and preventable are a common risk every day to life that can happen to almost every one, anywhere. The problem of road traffic incident is increasingly becoming a threat to public health and national development in many developing countries. Road traffic incidents contribute to poverty by causing deaths, injuries, disabilities, grief, lost of productivity and material damages. Road traffic incidents are the most frequent causes of injury-related deaths world wide ${ }^{1}$. According to the World Report on Road Traffic Injury Prevention ${ }^{2}$ traffic accidents account for about 3000 daily fatalities worldwide. Statistical projections show that during the period between 2000 and 2020, fatalities related to traffic incidents will decrease with about $30 \%$ in high income countries. The opposite pattern is expected in developing countries, where traffic accidents are expected to increase at a fast rate in the years to come. In developing countries the trend has reached an alarming state, but very little attention is paid to the problem ${ }^{3}$. There is evidence that using minimum safety standards, crash worthiness improvement in vehicles, seatbelts use laws and reduced alcohol use can substantially reduce deaths on the road 4 . The magnitude of Road traffic incidents and fatalities in India is alarming. In 2009, 4.22 lakh road traffic incidents and 1.27 lakh road traffic fatalities were reported $^{5}$.These numbers translate into one road incident every minute and one road incident death every four minutes. However, this is an underestimate, as not all injuries are reported to the police $^{5}$. Hilly regions are prone for RTA and there are very few number of studies in such areas. Therefore this study is under taken to identify the clinic - epidemiological profile of Road traffic incidents amongst patients admitted at Base hospital, Srinagar - Garhwal and to assess the factors associated with the causation of the same.

\section{METHODOLOGY:}

A model for traffic incident as inspired by the ecological model of a disease was developed by Jorgensen and Abane (1999) ${ }^{6}$ who made a heuristic adjustment of this basic model to suit road traffic accident analysis. The model is characterized by three main components:

1. The vehicle (corresponding to the vector in disease ecology) which describes vehicles into its composition, age, technical conditions and safety equipments like seat belts in a car.

2. The environment, comprising the road system and the wider physical and built up environment. The physical environment splits further into different aspects such as; Daylight and climate (weather conditions and road conditions), Spatial conditions (arrangements and Macro structures), Settlement pattern (Urban or rural / sparse or populated area), situation of areas of residence and working areas, Principle of traffic separation, topography and road constructions qualities.

3. The behavior of the population; including its characteristics such as age and sex ratio as well as attitudes and general traffic behavior. And it goes further into driving behavior, driving experience, driving style, risk compensation and risk driving (influence of alcohol and drugs).

Journal of Evolution of Medical and Dental Sciences / Volume 1 / Issue 3 / July- Sept 2012 
Superimposed on this model is a system of traffic laws, regulations and mode of enforcement designed to ensure that the population adheres to the controls and regulations so as to maintain some level of road safety i.e. traffic rules (speed restrictions, road signs), speed controls and convictions for various road traffic offences ${ }^{6}$. Based on this model this cross sectional study was done with the help a pretested questionnaire, in a tertiary care hospital in Garhwal. All cases of RTA coming to the tertiary care hospital during March 2011 to February 2012 were included in the study. Questions were asked for assessing various risk factors as per the above said model and data entry was done on excel and analyzed thereafter.

\section{ETHICAL CONSIDERATIONS:}

Ethical clearance from institutional review board/ institutional ethical committee was taken for the study. Written consent was sought from the all respondents. They were informed about the nature and the purpose of the survey.

\section{RESULTS:}

During the study period a total of 136 individuals came for the medical assistance (Figure1).117 were males 19 were females. Out of them 33 were drivers of the vehicle, which got the accident. The number of brought dead persons because of Road Traffic Incidents, in the aforesaid period was 23. Out of the brought dead individuals 5 were drivers of the vehicle. Maximum number of morbidity because of RTI is evident in the month of December. There is clustering of cases from the month of August to October when compared to other months of year (Figure-1).

Most of the drivers were literate. Out of 33 drivers interviewed only 3 (9\%) were illiterate. Nearly $40 \%$ of drivers were drunk/or using some other substance at the time of accident.50\% of drivers were $>40$ years of age. $15.8 \%$ of drivers were less than 20 years of age. Most of the drivers (51.5\%) who met the accident were having driving experience of $>5$ years. $12.1 \%$ of drivers were having driving experience of less than 1 year. Only $12.1 \%$ of drivers were using seat belts at the time of incident. $57.6 \%$ were having driving license and $54.5 \%$ were either refractive error or hearing impairment or both. Most of the respondents told that it was mistake of other drivers which led to the accident. High speed, Lack of sleep, effect of Alcohol and mechanical fault of vehicle were other reasons of accident as told by the drivers (Table-2). 78\% of victims were brought to the hospital with help of 108 helpline service. Rest $22 \%$ were came either by themselves or by other people (Figure-1).

Journal of Evolution of Medical and Dental Sciences / Volume 1 / Issue 3 / July- Sept 2012 


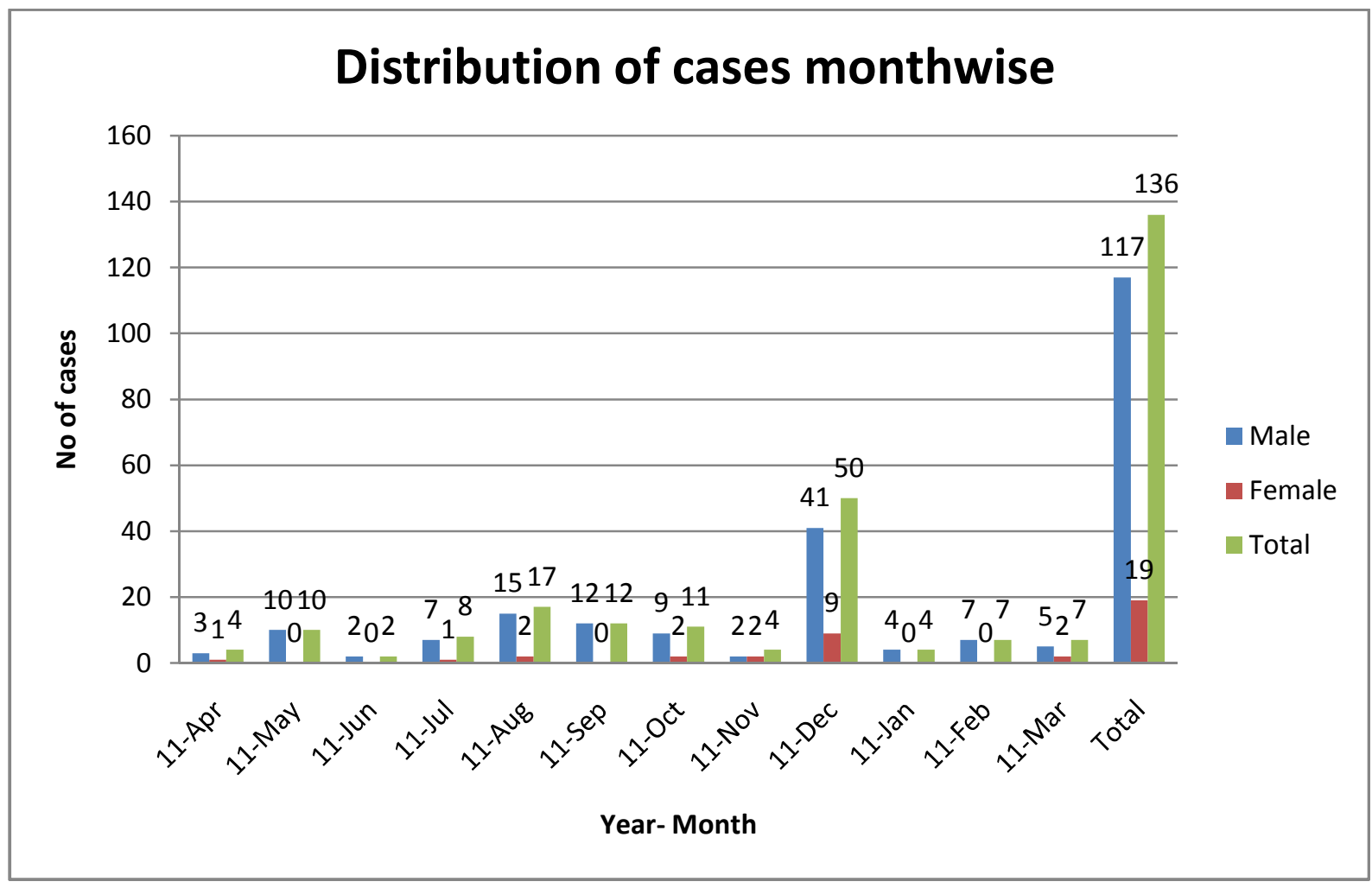

Figure -1: Monthly distribution of RTI cases

Figure-2: Mode of transfer to the hospital

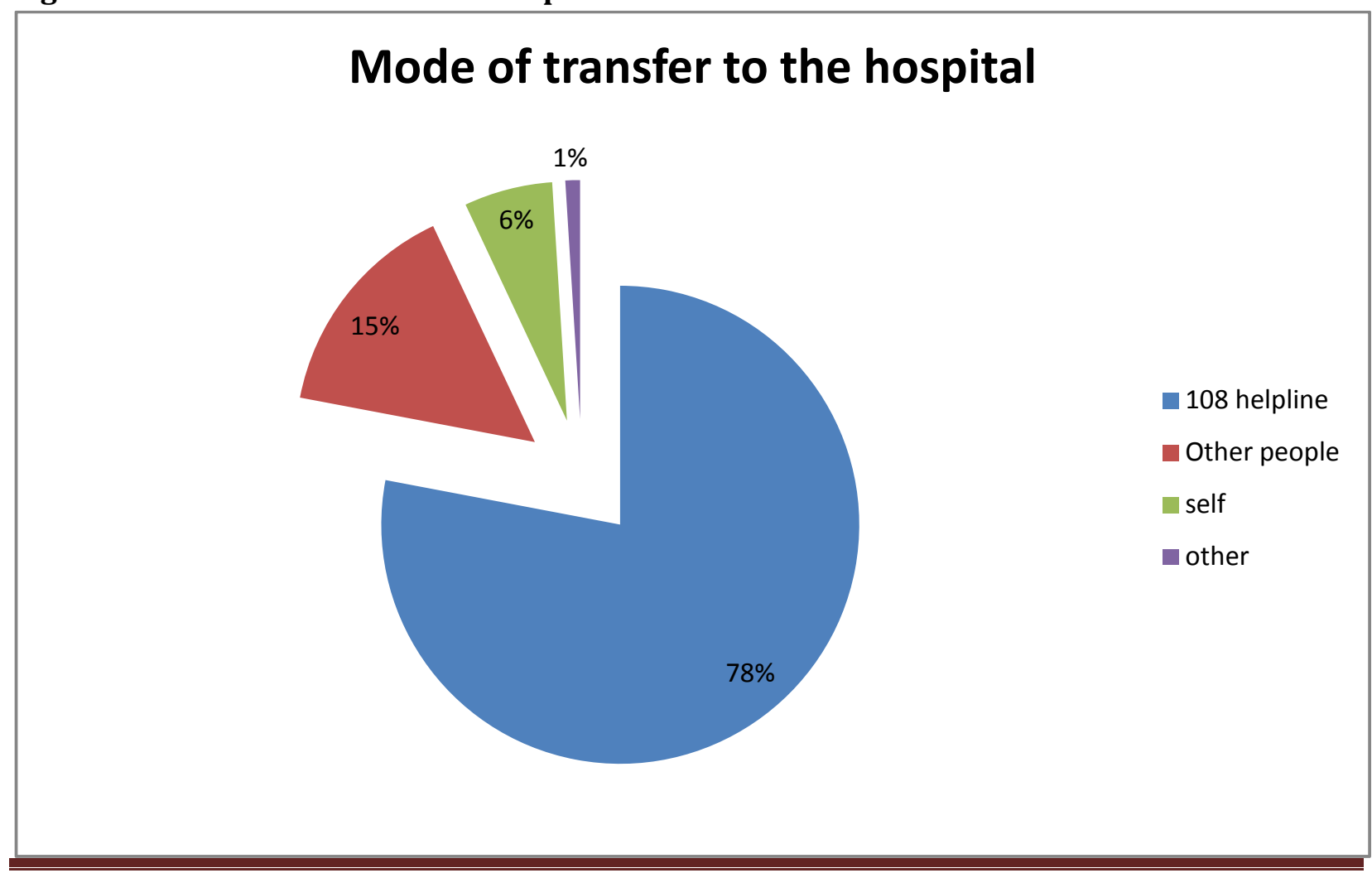

Journal of Evolution of Medical and Dental Sciences / Volume 1 / Issue 3 / July- Sept 2012 
Table-1: Clinico-epidemiological profile of RTI cases

\begin{tabular}{|c|c|c|c|}
\hline \multicolumn{2}{|c|}{ Drivers interviewed } & Yes & $\%$ age \\
\hline \multirow[t]{4}{*}{ Education(n=33) } & Illiterate & 03 & 9.1 \\
\hline & Up to 5 th std & 13 & 39.4 \\
\hline & $5-12$ th std & 16 & 48.4 \\
\hline & Graduate/Post graduate & 01 & 3.1 \\
\hline \multirow{3}{*}{$\begin{array}{l}\text { Age(n=38, } \\
\text { Including the } \\
\text { brought dead } \\
\text { drivers) }\end{array}$} & $<20$ years & 6 & 15.8 \\
\hline & $20-40$ years & 13 & 34.2 \\
\hline & $>40$ years & 19 & 50 \\
\hline \multicolumn{2}{|c|}{ Alcohol /other substance use at the time of accident( $n=33)$} & 13 & 39.4 \\
\hline \multirow[t]{2}{*}{ Driving experience } & $<1$ year & 4 & 12.1 \\
\hline & $1-5$ years & 12 & 36.4 \\
\hline$(n=33)$ & $>5$ years & 17 & 51.5 \\
\hline \multicolumn{2}{|c|}{ Seat belt use $(n=33)$} & 4 & 12.1 \\
\hline \multicolumn{2}{|c|}{ Driving license $(n=33)$} & 19 & 57.6 \\
\hline \multicolumn{2}{|c|}{ Refractive error /Hearing impairment / both $(n=33)$} & 18 & 54.5 \\
\hline \multirow{6}{*}{$\begin{array}{l}\text { Cause as told by } \\
\text { driver( Multiple } \\
\text { answers could } \\
\text { be given) }\end{array}$} & Mistake of others/Human error* $(n=33)$ & 23 & 69.7 \\
\hline & More speed & 14 & 42.4 \\
\hline & Lack of sleep & 11 & 33.3 \\
\hline & Alcohol use & 09 & 27.3 \\
\hline & Mechanical fault of the vehicle** & 09 & 27.3 \\
\hline & $\begin{array}{l}\text { Others including environmental } \\
\text { conditions }\end{array}$ & 04 & 12.1 \\
\hline
\end{tabular}

*Human error: wrongful U-turn by other vehicle, Wrongful overtaking by un-coming vehicle **Mechanical fault: break failure, burst tyre, and locked steering mechanism

Maximum number (47.8\%) of RTI morbidity was because of polytrauma associated. And upper limb injury was least responsible for the mortality.50\% of accidents took place in the evening Journal of Evolution of Medical and Dental Sciences / Volume 1 / Issue 3 / July- Sept 2012 
hours. $72.7 \%$ of vehicles were older than 5 years of age. Fall from hill was the mode of accident in most of the cases and the mortality and severe injuries were also more in fall from hillside, followed by accident from the sides and head on collision.

Table -2: Epidemiological profile of RTI cases

\begin{tabular}{|c|c|c|c|}
\hline \multicolumn{2}{|l|}{ Variable } & \multirow{2}{*}{$\begin{array}{l}\text { Number } \\
20\end{array}$} & \multirow{2}{*}{$\begin{array}{l}\% \text { age } \\
14.7\end{array}$} \\
\hline Injury( $n=136)$ & Involved head & & \\
\hline & Upper limb & 14 & 10.3 \\
\hline & Lower limb & 21 & 15.5 \\
\hline & Abdomen & 16 & 11.7 \\
\hline & Multiple / polytrauma & 65 & 47.8 \\
\hline \multirow[t]{4}{*}{ Time of accident $(\mathrm{N}=38)$} & $12 \mathrm{pm}-6 \mathrm{pm}$ & 14 & 36.8 \\
\hline & $6 \mathrm{pm}-9 \mathrm{pm}$ & 19 & 50.0 \\
\hline & 9pm-6am & 02 & 5.3 \\
\hline & $6 a m-12 \mathrm{pm}$ & 03 & 7.9 \\
\hline \multirow[t]{2}{*}{ Age of the vehicle $(\mathrm{N}=33)$} & $<5$ years & 09 & 27.3 \\
\hline & $>5$ years & 24 & 72.7 \\
\hline \multirow{5}{*}{$\begin{array}{l}\text { Type } \\
\text { collision/accident }(\mathrm{N}=38)\end{array}$} & Head on & 04 & 10.5 \\
\hline & From behind & 02 & 5.3 \\
\hline & From sides & 07 & 18.4 \\
\hline & Fall from hill & 18 & 47.4 \\
\hline & Other & 07 & 18.4 \\
\hline
\end{tabular}

\section{DISCUSSION:}

Maximum number of Morbidity because of RTI is evident in the month of December. It was fall of a bus, from the hill side leading to higher toll in mortality and morbidity in month of December. There is clustering of cases from the month of August to October when compared to other months of year. "Char dham yatra" which lead to sudden increase in number of vehicles on hillside and heavy rainy season both coincides with this period. These can be contributing factor for such clustering of cases. Most of the drivers were literate. Out of 33 drivers interviewed only 3 (9\%) were illiterate. Substance use including drinking behavior was noticed in 39\% of the drivers at the 
time of accident. Experienced drivers ( $>5$ years) met the accident in maximum number. Overconfidence leading to recklessness can be the reasons for such happening. $77.9 \%$ drivers were not using seat belt at the time of accident and when asked for the driving license only $42.4 \%$ could not produce the same. $50 \%$ of drivers who met the accident were $>40$ years of age. In the elderly visual impairment prevents adequate visual function, which may be responsible for the accident. When examined, 54.5\% were having either refractive error or hearing impairment or both. A study, which examined the association between visual impairment and RTI among 1,428 drivers seen at the accident and emergency department of a hospital in the United Arab Emirates, also identified visual impairment to be significant risk factors ${ }^{7}$. Likewise Davidson in his examination of the interrelationship between British drivers' visual abilities, age and RTI histories found strongest positive association between RTI variables and visual disabilities, among older drivers ${ }^{8}$. Most of the respondents told that it was mistake of other drivers which led to the accident. High speed, Lack of sleep, effect of Alcohol and mechanical fault of vehicle were other reasons of accident as told by the drivers. Study by Asogwa et $\mathrm{al}^{9}$ showed that commercial drivers drive for hours without sleep and food, until fatigue inevitably sets in and a crash may be the end result. Effect of alcohol or other substances was also substantiated by Lemoineet al ${ }^{10}$. Maximum number (47.8\%) of RTI morbidity was because of polytrauma associated. And upper limb injury was least responsible for the mortality. This is in contrast to the study by Biswas $\mathrm{G}^{11}$ who cited that the maximum (56.4\%) injuries were found on head and neck, followed by thorax (54.5\%) and abdomen (44.5\%). Other studies $^{12,13}$ also showed a high incidence of head injuries in their studies. $50 \%$ of accidents took place in the evening hours. Fall from hill was the mode of accident in most of the cases and the mortality and severe injuries were also maximum in such mode of accident followed by accident from the sides and head on collision.

\section{CONCLUSION:}

During "Char Dham Yatra" period and rainy seasons there is clustering of cases. Special efforts should be done during this period. Strong vigilance of drivers for alcohol use, presence of driving license, compulsory use of seat belts, premedical checkup for refractive errors, must be ensured. The role of 108 helpline ${ }^{14}$ cannot be ruled out and strengthening of this service can be of paramount importance. All These measures may prove valuable and morbidity and mortality can be minimized.

\section{ACKNOWLEDGEMENT:}

The author acknowledges medical social workers of department of community medicine, Veer Chandra singh Garhwali govt. medical college, Srinagar, Garhwal for their work and support in the study. The author also acknowledges the respondents who formed the building blocks for the study.

\section{REFERENCES:}

1. Astrom, J. S, Kent, M.P. and Jovin, R. D. (2006) Signatures of Four Generations of Road Safety Planning in Nairobi City, Kenya In: Journal of Eastern African Research and Development. Vo. 120, pp. 186-201.

Journal of Evolution of Medical and Dental Sciences / Volume 1 / Issue 3 / July- Sept 2012 
2. Peden, M. (Ed), (2004), World Report on Road Traffic Injury Prevention. World Health Organisation, Geneva.

3. Odero, W., Garner, P. and Zwi, A. (1997). Road traffic injuries in the developing countries: a comprehensive review of epidemiological studies. Journal of Tropical Medicine and International Health. 2(5), 445-460.

4. Leon, S.R. (1996).Reducing death on the Road.The effects of minimum safety standards, Unpublicised crash test, seat belts and alcohol. Am J Public Health; 86(1):31-3.

5. Road Accidents in India, 2009. Transport Research Wing, Ministry of Road Transport \& Highways, Government Of India, New Delhi.

6. Jorgensen, S. H., and Abane, A. M. (1999). A comparative study of urban traffic accidents in developing and developed countries: Empirical observations and problems from Trondheim (Norway) and Accra (Ghana). Bulletin of Ghana Geographical Association. No. 21, 113-128.

7. Bener A, Ahmad MF, El-Tawil MS, Al- Bakre S. Visual impairment and motor vehicle accident. Middle East Journal of Emergency Medicine. 2004; 4: 1-9

8. Davidson PA. Inter-relationships between British drivers' visual abilities, age and road accident histories. Opthalmic and Physiological Optics. 1985; 5:195-204.

9. Asogwa SE. Kola nut and road traffic accidents in Nigeria. American Journal of Public Health. 1978; 68:1228.

10. Lemoine P, Ohayon M. Abuse of psychotropic drugs during driving. Encephale. 1996; 22:1-6.

11. Biswas G, Verma SK, Sharma JJ, Aggarwal NK. Pattern of Road Traffic Accidents in North East Delhi. Journal of Forensic Medicine \& Toxicology.2003; 20(1):27-32.

12. Sahdev P, Laeque MD, Singh B and Dogra TD. Road Traffic Accidents in Delhi, causes, injury pattern and incidence of preventable deaths. Accid Anal Prev 1994; 26:12-18.

13. Salgado MSL, Colombage SM. Analysis of fatalities in road accidents. For Sci Int .1998; 36:91-96.

14. In Uttarakhand, Emergency helpline Number "108" to tackle disaster calls, complaints. Available at http://www.indiahillstoday.com/2010/10/12/in-uttarakhand-emergencyhelpline-number-108-to-tackle-disaster-calls-complaints/ 